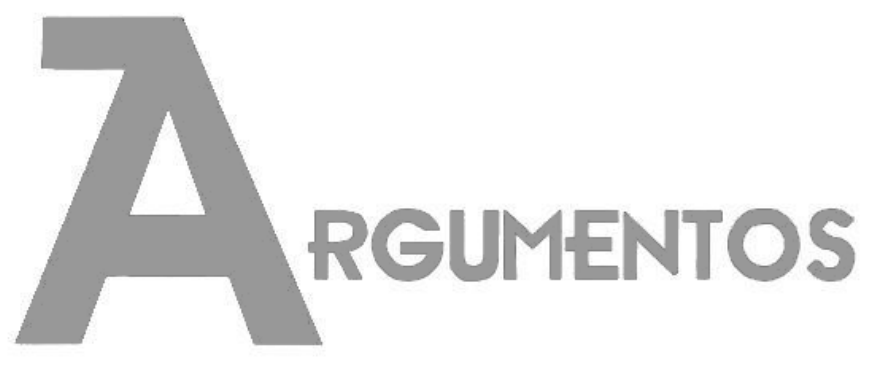

\title{
Governança dos comuns e conflitos na gestão da bacia do Rio Itanhém no extremo sul da Bahia
}

\author{
Fernando Rios de Souza ${ }^{1}$ \\ Herbert Toledo Martins ${ }^{2}$
}

Recebido em: 01/10/2019

Aprovado em: 20/12/2019

\begin{abstract}
Resumo: $\mathrm{O}$ artigo analisa o Comitê das Bacias Hidrográficas dos rios Peruípe, Itanhém e Jucuruçu (CBHPIJ), localizado no extremo sul da Bahia, Brasil. O foco da investigação é compreender as razões pelas quais o referido Comitê, após sete anos da sua criação, em dezembro de 2012, não desenvolve as ações de gestão ambiental que garanta a preservação destes rios, em particular do rio Itanhém foco da pesquisa. O estudo segue o modelo de Análise de Desenvolvimento Institucional para Sistemas Sócioecológicos (IAD-SES Framework) construído por Ostrom (1990, 2009), que resulta em oito princípios de design representando um tipo ideal de análise das relações entre sociedade, economia e meio ambiente. Tal modelo permite comparar a realidade ao tipo ideal e, dessa forma, compreender as dificuldades enfrentadas pelo Comitê. Foram entrevistados 14 membros da gestão e 10 usuários de água. Os achados da pesquisa revelam que o Comitê carece do reconhecimento dos usuários; que todos precisam conhecer seus limites e condições biofísicas necessitam fazer valer com equidade as regras, e respeitar a heterogeneidade da comunidade envolvida conforme suas diversas narrativas.
\end{abstract}

Palavras-chave: Conflito socioambiental, Governança dos Comuns, Comitê de Bacias, Rio Itanhém, Extremo sul da Bahia.

\section{Gobernanza de los bienes comunes y los conflictos en la gestión de la cuenca del río Itanhém en el extremo sur de Bahía}

Resumen: El artículo analiza el Comité de Cuencas del Río Peruípe, Itanhém y Jucuruçu (CCRPIJ), ubicado en el extremo sur de Bahía, Brasil. El objetivo de la investigación es comprender las razones por las cuales dicho Comité, después de siete años de su creación, en diciembre de

\footnotetext{
1 Programa de Pós-Graduação em Estado e Sociedade. Universidade Federal do Sul da Bahia E-mail: rios.fernando@hotmail.com. ORCID: https://orcid.org/0000-0002-0418-5546.

2 Programa de Pós-Graduação em Estado e Sociedade. Universidade Federal do Sul da Bahia. E-mail: herbert@ufsb.edu.br. ORCID: https://orcid.org/0000-0002-4096-6104.
} 
2012, no desarrolla acciones de gestión ambiental que garanticen la preservación de estos ríos, en particular el foco del río Itanhém de la investigación. El estudio sigue el Modelo de Análisis de Desarrollo Institucional del Marco IAD-SES (Marco IAD-SES) construido por Ostrom (1990, 2009), que da como resultado ocho principios de diseño que representan un tipo ideal de análisis de las relaciones entre sociedad, economía y medio ambiente. Dicho modelo permite comparar la realidad con el tipo ideal y, por lo tanto, comprender las dificultades que enfrenta el Comité. Catorce miembros de la gerencia y 10 usuarios de agua fueron entrevistados. Los resultados de la investigación revelan que el Comité carece de reconocimiento del usuario; que todos necesitan conocer sus límites y condiciones biofísicas, deben hacer cumplir las reglas de manera justa y respetar la heterogeneidad de la comunidad involucrada de acuerdo con sus diversas narrativas.

Palabras-clave: Conflicto socioambiental, Gobierno de los Comunes, Comité de Cuenca, Río Itanhém, Bahía más austral.

\title{
Governance of the commons and conflicts in the management of the Itanhém River basin in the extreme south of Bahia
}

\begin{abstract}
The article analyzes the Peruípe, Itanhém and Jucuruçu River Basins Committee (PIJRBC), located in the extreme south of Bahia, Brazil. The focus of the investigation is to understand the reasons why the said Committee, after seven years of its creation, in December 2012, does not develop environmental management actions that guarantee the preservation of these rivers, in particular the Itanhém river focus of the research. The study follows the IAD-SES Framework Institutional Development Analysis Model (IAD-SES Framework) built by Ostrom (1990, 2009), which results in eight design principles representing an ideal type of analysis of the relationships between society, economy and environment. Such model allows to compare reality to the ideal type and, thus, to understand the difficulties faced by the Committee. Fourteen management members and 10 water users were interviewed. The research findings reveal that the Committee lacks user recognition; that everyone needs to know their limits and biophysical conditions, need to enforce the rules fairly, and respect the heterogeneity of the community involved according to their various narratives.
\end{abstract}

Keywords: Socio-environmental conflict, Commons Governance, Basin Committee, Itanhém River, Southernmost Bahia.

\section{Introdução}

O artigo analisa o Comitê de Bacias Hidrográficas dos rios Peruípe, Itanhém e Jucuruçu (CBHPIJ), localizado na região do extremo sul da Bahia. O centro de atenção do estudo reside nos atores que exercem influência direta no Comitê. Por intermédio de entrevistas estruturadas pretende-se compreender as razões pelas quais o referido Comitê, após sete anos da sua criação, em dezembro de 2012, não desenvolve as ações de gestão ambiental que garanta a preservação destes rios, em particular do rio Itanhém foco desta pesquisa. É comum a ausência de matas ciliares, assoreamentos gradativos, contaminação por agrotóxicos, nascentes prejudicadas e poluição das mais diversas formas. Sob a luz do modelo de análise institucional para sistemas socio ecológicos (IAD- 
Dossiê | Governança dos comuns e conflitos na gestão da bacia do Rio Itanhém no extremo sul da Bahia (SOUZA, Fernando Rios; MARTINS, Herbert Toledo)

SES framework), ${ }^{3}$ argumentamos que os fatores e condições que impedem o efetivo funcionamento do Comitê residem no conflito existente entre a realidade prática dos usuários dos recursos comuns do rio Itanhém que envolve cultivo de plantações, criação de gado e a relação direta com a água, e a realidade vivenciada pelos plenários e reuniões do Comitê, onde se discute regras e normas no plano abstrato e que não se efetivam na experiência cotidiana dos usuários. Na ausência de regras claras e efetivas, o usuário dos recursos comuns do rio Itanhém é colocado diante do dilema da ação coletiva (Olson 1965), na medida em que não pode limitar a utilização da água ou a derrubada da mata ciliar para pastagem ou plantações. E se ele limitar seu próprio uso destes recursos comuns somente ele sairá perdendo, ao passo que a utilização excessiva destrói o recurso comum de que todos dependem.

De acordo com Acserald (2004), a sociologia da questão ambiental encontra uma certa dificuldade em definir "conflitos ambientais" enquanto um objeto científico. Dada a complexidade e diversidade de conflitos envolvendo o meio ambiente torna-se difícil caracterizar o que é específico do conflito ambiental. Em virtude da variedade de conflitos há, portanto, diversas e diferentes teorias ou concepções explicativas: evolucionistas, funcionalistas, economicistas, estrategistas em relação aos modelos de desenvolvimento, cada qual à sua maneira buscam caracterizar a especificidade dos conflitos. ${ }^{4}$ Em função dessa pluralidade de concepções, Ascerald (2004) faz o uso da noção de campo de Bourdieu, campo dos conflitos ambientais, concebendo campo como um espaço social "relativamente autônomo, um microcosmo dotado de suas lei próprias" (BOURDIEU, 2004, p. 20). Campo é um lugar de lutas "entre os agentes que o integram e que buscam manter ou alcançar determinadas posições. Essas posições são obtidas pelas disputas de capitais específicos valorizados de acordo com as características de cada campo" (PEREIRA, 2015, p. 341). É a posição que os agentes ocupam na "estrutura das relações objetivas" do campo que determina ou orienta as tomadas de posição dos agentes. O campo (científico, literário, artístico, ambiental, etc.) dever ser concebido de forma relacional em constante movimento. Uma arena de disputas. Cada campo tem uma forma específica de capital, seja ele material ou

\footnotetext{
${ }^{3}$ Ostrom, Elinor. "A General Framework for Analyzing Sustainability of Social-Ecological Systems". Science, v. 325 , n. 5939, 2009, 419-22.

${ }^{4}$ Para a análise mais detalhada dessas teorias ler ACSERALD, 2004. A discussão sobre conflitos ambientais foi extraída de SANTOS \& MARTINS (2019).
} 
simbólico. E é o domínio desse capital que “proporciona autoridade e contribui para definir não somente as regras do jogo, mas também suas regularidades, as leis segundo as quais vão se distribuir os lucros nesse jogo" (BORDIEU, 2004, p. 27).

Desse modo, ao utilizar a noção de campo, Ascerald (2004) propõe analisar os conflitos ambientais como decorrentes, por um lado, da distribuição de poder entre os atores sociais "sobre os diferentes tipos de "capital", incluindo o que podemos chamar, para os efeitos da questão ambiental, de "capital material"”, isto é, a capacidade dos atores de "terem acesso a terra fértil, a fonte de água, aos recursos vivos, aos pontos dotados de vantagens locacionais" e, por outro lado, conflitos ambientais poder ter origem nas "representações, valores, esquemas de percepção e ideias que organizam visões de mundo e legitimam os modos de distribuição de poder". Assim, portanto, concebendo os conflitos ambientais como algo que ocorre no espaço social de um campo de disputas, os conflitos ambientais dever ser analisados como decorrentes das lutas sociais, econômicas e políticas "pela apropriação de diferentes tipos de capital, pela mudança ou conservação da estrutura de distribuição de poder"; e de lutas simbólicas "para impor as categorias que legitimam ou deslegitimam a distribuição de poder sobre os distintos tipos de capital" (ASCERALD, 2004, p. 23). Neste sentido, para o autor conflitos ambientais envolvem:

grupos sociais com modos diferenciados de apropriação, uso e significação do território, tendo origem quando pelo menos um dos grupos tem a continuidade das formas sociais de apropriação do meio que desenvolvem ameaçada por impactos indesejáveis - transmitidos pelo solo, água, ar ou sistemas vivos - decorrentes do exercício das práticas de outros grupos. 0 conflito pode derivar da disputa por apropriação de uma mesma base de recursos ou de bases distintas, mas interconectadas por interações ecossistêmicas mediadas pela atmosfera, pelo solo, pelas águas, etc. (ACSERALD, 2004, p.15 e 26).

Nesta perspectiva, o estudo discute a "tragédia ambiental" que vive o rio Itanhém com foco nos conflitos existente entre as ações dos usuários que seguem suas próprias práticas, e as dos membros do Comitê que propõem a gestão coletiva do bem comum. De um lado, os usuários (agricultores) que utilizam a água para fins de irrigação e áreas para pastagem e plantações, juntos, são os principais apropriadores dos recursos comuns. De outro, os gestores que exercem influência direta no processo deliberativo 
Dossiê | Governança dos comuns e conflitos na gestão da bacia do Rio Itanhém no extremo sul da Bahia (SOUZA, Fernando Rios; MARTINS, Herbert Toledo)

do referido Comitê. Ao todo foram entrevistados 10 agricultores e 14 membros do Comitê, que responderam presencialmente as perguntas elaboradas em questionário específico extraído do modelo de Análise de Desenvolvimento Institucional para Sistemas Socioeconômicos (IAD-SES Framework) construído por Ostrom (1990, 2009). A partir desse modelo são formulados oito princípios de design relacionados a instituições robustas de recursos comuns. Dada a grande variedade de problemas ecológicos que os indivíduos enfrentam em diversas escalas, os princípios de design constituem parâmetro ideal de governança e se apresenta como um instrumento para avaliar se o arranjo coletivo terá ou não sucesso na implementação de suas regras sustentáveis. No espaço deste artigo será apresentada uma interpretação qualitativa dos resultados da pesquisa. A relevância do estudo reside na aplicação do modelo de análise acima referido no caso de um Comitê de bacia hidrográfica da região nordeste do Brasil contribuindo, dessa forma, para a compreensão dos problemas enfrentados pelo mesmo, além de ampliar o estoque de conhecimento sobre gestão de bacias hidrográficas no país.

Desse modo, o presente artigo se insere no campo de estudos dos Common Pool Resources (CPR), e será analisado a partir do embasamento teórico-metodológico proposto por Ostrom (1990), e está organizado em quatro seções, além dessa introdução. Na primeira seção, discute-se o embasamento teórico que ilumina o problema, com ênfase nos pressupostos da "Tragédia dos Comuns" de Hardin (1968), na lógica da ação coletiva de Olson (1965), e na governança dos comuns de Ostrom (1990). Na segunda seção, aplicamos o método desenvolvido por Elinor Ostrom (1990, 2009) de análise institucional para sistemas socio ecológicos (IAD-SES framework) na realidade do CBHPIJ, com destaque nas relações entre os usuários e os membros líderes do Comitê. Na terceira e última seção, são analisados os resultados e feitas as discussões da pesquisa, com foco nos conflitos entre as práticas adotadas pelos agricultores usuários de recursos comuns e as regras discutidas e emanadas pelo CBHPIJ, tendo como padrão comparativo o tipo ideal de uma instituição robusta elaborados por Ostrom (1990), anunciados pelos 8 princípios de design.

\section{O dilema da ação coletiva na Bacia do rio Itanhém, Brasil}


O rio Itanhém tem grande importância socioeconômica na região do extremo sul da Bahia. Com área de bacia de $6.042 \mathrm{~km}^{2}$, e com população aproximada de 230.000 habitantes, drena a maior parte dos municípios de Alcobaça, Teixeira de Freitas e Medeiros Neto, no estado da Bahia, e ainda no estado de Minas Gerais os municípios de Bertópolis, Santa Helena de Minas, Machacalis, e Fronteira dos Vales, conforme Figura 1 seguinte.

Figura 01. Mapa Hipsométrico da bacia do rio Itanhém.

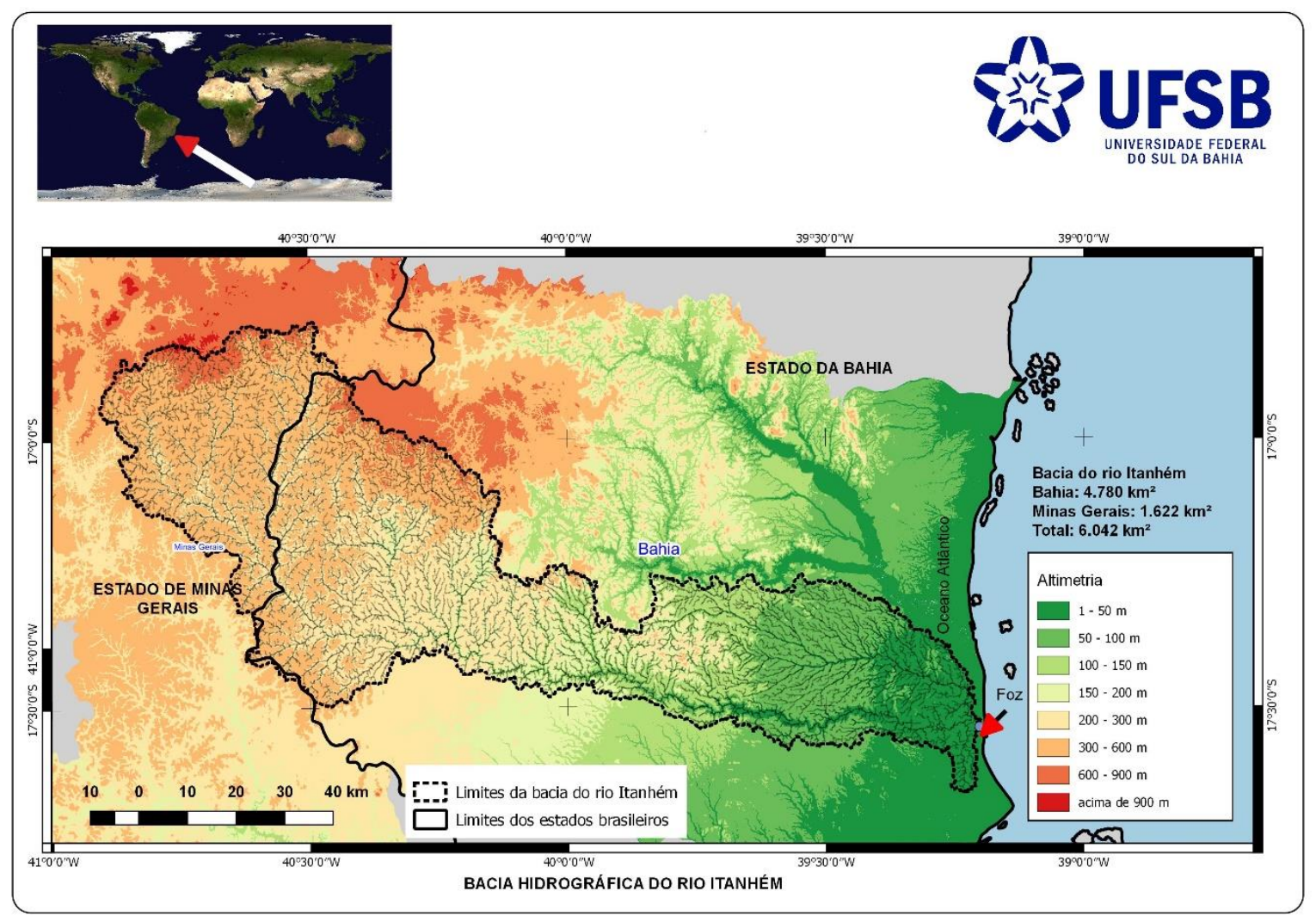

Fonte: Elaboração própria.

O rio Itanhém, infelizmente, sofre com as ações de usuários egoístas que ainda não estão sob a influência das regras coletivas de cooperação sustentável. Observa-se a ausência de vegetação ciliar, assoreamento gradativo, contaminação de águas por agrotóxicos e cargas orgânicas, além de moradias irregulares ao longo de seu leito. Dessa maneira, a configuração atual do rio em tela ilustra o problema da ação coletiva trazido por Olson (1965). O autor analisou os dilemas enfrentados pelos cidadãos que desejam obter algum bem público por meio da ação coletiva. Observou que a ação 
Dossiê | Governança dos comuns e conflitos na gestão da bacia do Rio Itanhém no extremo sul da Bahia (SOUZA, Fernando Rios; MARTINS, Herbert Toledo)

coletiva é um problema porque os custos da contribuição (serão individuais) e estão concentrados, enquanto os benefícios (coletivos) são difusos. Em outras palavras, o custo dispendido pelo indivíduo é concentrado e produz melhor resultado se fosse para ele próprio. No entanto, se ele praticar a mesma ação para o coletivo, não auferirá os mesmos benefícios, pois estes serão pulverizados. Na ausência de cooperação (um processo de confiança) o indivíduo tende a maximizar o seu interesse individual. Olson (1965) identificou três condições que influenciam as perspectivas de ação coletiva: tamanho do grupo, heterogeneidade e incentivos seletivos. O tamanho do grupo influencia na escolha da ação individual. Quanto maior o grupo, maior a dispersão dos resultados, menor o resultado individual. Dessa forma, a probabilidade de ação coletiva diminuirá à medida que o tamanho do grupo aumenta. Olson (1965) conclui que a ação coletiva será mais fácil de ser alcançada apenas em pequenos grupos, já que nestes os interesses são mais iguais, e ainda é mais fácil a aplicação dos incentivos seletivos. Com relação à heterogeneidade, quanto maior o grupo, menores as chances da ação coletiva, já que cresce também o número de indivíduos com interesses diferentes. A ação coletiva também pode ser estimulada por incentivos seletivos, mas tais atos não resolvem o problema fundamental: o comportamento tendente a ser individual. Para Olson (1965) o individualismo é a chave para a compreensão das ações sociais, posto que o bem comum não seria suficiente para induzir a ação do indivíduo e, por isso seriam necessários incentivos seletivos, ou seja, uma espécie de benefício aos participantes na busca do bem coletivo, da mesma forma que seria necessário a coerção sobre os que se recusam a colaborar. Sem regulamentações impostas externamente, a teoria prevê que os recursos naturais utilizados em conjunto serão grosseiramente mal administrados.

Nessa lógica, é inevitável não se pensar que o interesse individual prevalecerá quando cada um, na tentação da oportunidade, retirar sempre mais uma unidade de um recurso limitado. Neste contexto, o biólogo Hardin (1968) argumentou sobre a inevitabilidade da destruição ambiental nos casos de exploração de recursos naturais quando submetidos ao uso desregrado. $O$ autor elabora um prognóstico trágico e afirma que os recursos naturais, quando explorados em sistemas coletivos ineficazes, tenderiam ao esgotamento, inevitavelmente. Impulsionado por uma racionalidade individualista, o indivíduo buscaria maximizar a satisfação das suas próprias preferências, produzindo um resultado sub-ótimo e eventualmente catastrófico para a 
Dossiê | Governança dos comuns e conflitos na gestão da bacia do Rio Itanhém no extremo sul da Bahia (SOUZA, Fernando Rios; MARTINS, Herbert Toledo)

coletividade e para si mesmo. Assim, Hardin propõe duas alternativas para solucionar tal dilema. Na primeira, as áreas ou os recursos naturais deveriam ser privatizadas, pois sob o regime privado as formas de uso são rigorosamente controladas pelos interessados. Na segunda, o Estado deveria ser o administrador oficial e impor as regras de uso. Essas duas opções, na visão de Hardin, garantiriam a disponibilidade dos recursos naturais. Desde que foi formulado esse raciocínio conquistou adeptos, mas também muitos pesquisadores o criticaram (AZEVEDO, MARTINS, DRUMMOND, 2009). Nas últimas décadas, o raciocínio de Hardin tem sido criticado por estudos sobre sistemas comunais de uso e manejo dos recursos naturais, o que contribuiu para ampliar o escopo e a base teórica do campo de estudos que se convencionou chamar de Common Property Resources ou Common Pool Resources - CPR. As questões focalizadas nesse campo de estudo referem-se à identificação e à investigação dos fatores que levam ao sucesso ou ao fracasso dos arranjos coletivos, ao desenho institucional dessas experiências, a partir do exame da sua organização, dos atores envolvidos, das regras de acesso e exclusão de usuários e dos mecanismos de cumprimento das regras estabelecidas. A principal e influente pesquisadora desse campo é Elinor Ostrom (1990), cujos estudos ao redor do mundo demonstram que é possível por meio da organização e participação coletiva, estabelecer regras, monitorálas e fazê-las cumprir; penalizando os desvios, de modo que a sociedade possa autopromover suas escolhas numa boa via de gestão ambiental sustentável.

Nesta perspectiva, sobre a "tragédia dos comuns", Ostrom (1999) identificou caminhos alternativos. Mostrou que uma solução para o dilema dos comuns pode ser a cooperação, desde que, e, principalmente, a maioria dos envolvidos compartilhem o sentimento de que se não adotarem novas posturas irão sucumbir. Esta alternativa assume, entretanto, que os seres humanos podem não ser capazes de analisar todas as situações completamente, mas farão um esforço para resolver os problemas complexos, aprendendo normas de comportamento, particularmente as de reciprocidade. Ostrom (1990) acreditou que aqueles que dependem dos recursos comuns não ficam para sempre presos em situações cada vez mais agravantes. De certa forma, lento ou rápido, a governança torna-se um processo adaptativo que envolve múltiplos atores em diversos níveis sociais. 
Dossiê | Governança dos comuns e conflitos na gestão da bacia do Rio Itanhém no extremo sul da Bahia (SOUZA, Fernando Rios; MARTINS, Herbert Toledo)

Ostrom (1990), estudando práticas ao redor do mundo que deram certo pela via coletiva elaborou princípios comuns aos agrupamentos de sucesso, robustos e resilientes frente aos problemas cotidianos. Desse modo, elaborou um "tipo ideal" de práticas que consistem em oito princípios de gestão ambiental do que seria uma governança eficiente (OSTROM, 2009). Os princípios são condutas necessárias ao grupo e ao indivíduo, e dizem respeito às informações que ele carrega, e suas ações práticas com o meio socioeconômico. Resumidamente são os seguintes os oito princípios de design:

1. Limites bem definidos: Os limites de um recurso devem ser claramente definidos, bem como o conjunto de indivíduos com direitos sobre o recurso. A imposição de regras de governança fica mais fácil quando os limites são bem definidos.

2. Equivalência Proporcional entre Custos e Benefícios: As regras em uso devem proporcionar benefícios a um recurso comum de forma proporcional aos custos necessários para o funcionamento destas regas. $O$ desequilíbrio pode levar alguns participantes a se recusarem a obedecer a regras que consideram injustas.

3. Acordos de Escolha Coletiva: A maioria dos indivíduos afetados pela regulação dos recursos deve participar na elaboração de suas regras. A participação aumenta a probabilidade de as regras serem consideradas justas pelos participantes.

4. Monitoramento: O monitoramento confiável aumenta a confiança entre os usuários de que eles podem cooperar sem o medo de que os outros não estejam cooperando.

5. Sanções graduadas: As sanções para as regras violadas devem ser graduadas pois incentivam as pessoas não quebrarem regras e a se adequar e, desta forma, voltar ao ciclo de confiança contínua. 
6. Mecanismos de Resolução de Conflitos: Deve haver arenas locais rápidas e de baixo custo para resolver conflitos entre usuários ou entre usuários e funcionários.

7. Reconhecimento Mínimo de Direitos: Os direitos dos usuários de fazer suas próprias regras devem ser reconhecidos pelo governo.

8. Esforços Cooperados: Quando os recursos comuns fazem parte de um sistema maior, as atividades de controle devem ser organizadas de forma cooperada entre as várias entidades sociais.

Nesta perspectiva, sob o apoio dos pressupostos da "Governança dos Comuns", parte-se do pressuposto teórico de que as práticas de gestão ambiental do rio Itanhém emanadas do CBHPIJ são falhas porque os usuários (agricultores) não recebem incentivos a praticar atos sustentáveis combinados com as regras teóricas impostas. Dessa forma, o usuário não é motivado a desviar da regra da tragédia, a alterar a prática da ação individual em busca de resultados a curto prazo. $O$ indivíduo se movimenta fora do contexto coletivo. Este conflito de gestão gera o ciclo que ambientalmente é insustentável. O método seguinte mostra que um dos motivos deste distanciamento são os altos custos em seguir as regras das instituições coletivas de gestão.

\section{Método}

Após apresentado o problema e os pressupostos teóricos, pretendemos agora compreender a realidade prática, o conflito, o distanciamento entre o Comitê e as ações realizadas pelos usuários. Buscamos entender o conjunto de informações que chegam até os usuários do sistema de recursos, e a forma que essas informações os motivam a decidir pela opção sustentável ou não. Para tanto, utiliza-se do método de Análise de Desenvolvimento Institucional para Sistemas Socioeconômicos (IAD-SES Framework) construído por Ostrom (1990, 2009). Tal modelo consiste em uma interpretação das relações entre sociedade, economia e meio ambiente. A análise de desenvolvimento 
institucional em tela considera diversos fatores na análise da gestão de um recurso de uso comum ou de um sistema socio ecológico. Trata-se, na verdade, de um modelo construído a partir de estudos ao redor do mundo, isto é, uma estrutura (framework) para a análise de qualquer recurso de uso comum (ver Quadro 1). A autora sugere que se leve em consideração as configurações ou aspectos sociais, econômicos e políticos. A partir daí, o recurso em estudo sob o Comitê da bacia do rio Itanhém é analisado sob quatro aspectos ou subníveis, a saber: Sistema de Recursos (SR), Unidade de Recursos (UR), Sistema de Governança (SG) e Usuários (U). Cada um desses ainda se desdobrando em outros, conforme Quadro 1.

Estas seriam, na concepção de Ostrom (1990), as variáveis que todo estudo sobre a governança de um recurso de uso comum deveria levar em consideração. É desse framework, portanto, dessa estrutura de análise como tipo ideal que elaboramos as perguntas dos questionários aplicados nesta pesquisa.

Quadro 1. Fatores hipotéticos que afetam a administração do sistema de irrigação Configurações Sociais, Econômicas e Políticas

\begin{tabular}{|c|c|}
\hline Sistema de Recursos (SR) & Sistema de Governança (SG) \\
\hline SR1-Setor: Água & SG1 - Organizações governamentais \\
\hline SR2 - Clareza dos limites do sistema & SG2 - Organizações não governamentais \\
\hline SR3 - Tamanho do sistema de irrigação & SG3 - Estrutura de grupos de uso \\
\hline SR4 - Infraestrutura de água & SG4 - Direitos de propriedade \\
\hline SR4-a- mão de obra & $\begin{array}{l}\text { SG4-a- Direitos de propriedade para } \\
\text { infraestrutura }\end{array}$ \\
\hline SR4-b-Canais & $\begin{array}{l}\text { SG4-b-Direitos de propriedade para a } \\
\text { água }\end{array}$ \\
\hline SR4-c-Estruturas de controle & SG5 - Regras Operacionais \\
\hline SR5-d-Estradas & SG6 - Regras de escolha coletiva \\
\hline
\end{tabular}


Dossiê | Governança dos comuns e conflitos na gestão da bacia do Rio Itanhém no extremo sul da Bahia (SOUZA, Fernando Rios; MARTINS, Herbert Toledo)

\begin{tabular}{|c|c|}
\hline SR6-e-Comunicações & SG7 - Regras constitucionais \\
\hline $\begin{array}{l}\text { SR5 - Escassez: abastecimento relativo de } \\
\text { água }\end{array}$ & $\begin{array}{l}\text { SG8 - Processos de monitoramento \& } \\
\text { sancionamento }\end{array}$ \\
\hline SR6 - Propriedades de equilíbrio & Usuários (U) \\
\hline SR7- Previsibilidade da oferta & U1 - Número de usuários \\
\hline SR7-a-sazonal & $\begin{array}{l}\text { U1-a- Número de usuários em todo o } \\
\text { sistema }\end{array}$ \\
\hline SR7-b-Interanual & $\begin{array}{l}\text { U1-b-Número de usuários em unidades } \\
\text { locais }\end{array}$ \\
\hline SR8 - Características de armazenamento & U2 - Atributos socioeconômicos dos usuários \\
\hline SR9 - Localização & U2-a-Riqueza \\
\hline Unidades de Recurso (UR) & U2-b-Heterogeneidade \\
\hline UR1 - Mobilidade da unidade de recursos & U2-c- Posse da Terra \\
\hline $\begin{array}{l}\text { UR2 - Disponibilidade de água por } \\
\text { temporada }\end{array}$ & U2-d-Estabilidade do Grupo \\
\hline $\begin{array}{l}\text { UR3 - Interação hidrológica entre unidades } \\
\text { de irrigação }\end{array}$ & U3 - História da irrigação \\
\hline UR3-a-Interação dentro de um sistema & U4 - Localização \\
\hline UR4-b- Interação entre sistemas & U5 - Liderança \\
\hline UR4 - Valor econômico da produção & U6 - Normas compartilhadas/Capital Social \\
\hline \multirow[t]{2}{*}{$\begin{array}{l}\text { UR7 - Distribuição espacial e temporal da } \\
\text { água }\end{array}$} & U7- Conhecimento de irrigação \\
\hline & $\begin{array}{l}\text { U8 - Dependência de irrigação } \\
\text { U9-Tecnologia usada }\end{array}$ \\
\hline
\end{tabular}

Fonte: Adaptado de Meinzen-Dick, R. (2007). 
Dossiê | Governança dos comuns e conflitos na gestão da bacia do Rio Itanhém no extremo sul da Bahia (SOUZA, Fernando Rios; MARTINS, Herbert Toledo)

Desse modo, com base no modelo exposto acima, e preocupados com os conflitos de interesses entre os usuários e os membros da gestão do Comitê, da predominância prática dos comportamentos egoístas individuais, discutimos a seguir o distanciamento entre usuários (agricultores) e o corpo da Diretoria do CBHPIJ, buscando compreender os fatores e condições que impedem o funcionamento do Comitê, comparando a realidade dos usuários e dos membros da Diretoria Executiva do CBHPIJ, com os oito princípios de design de Ostrom (1990), conforme Quadro 2, a seguir.

Quadro 2. Os Princípios de Design e a realidade dos Usuários e Diretoria do CBHPIJ

\begin{tabular}{|c|c|c|}
\hline $\begin{array}{l}\text { Princípios de } \\
\text { Design }\end{array}$ & Realidade dos usuários & Diretoria do CBHPIJ \\
\hline $\begin{array}{l}\text { Princípio } 1 . \\
\text { Clareza nos } \\
\text { limites } \\
\text { biofísicos e } \\
\text { sociais. }\end{array}$ & $\begin{array}{l}\text { Os usuários enxergam a bacia } \\
\text { apenas no horizonte de suas } \\
\text { propriedades. As regras que eles } \\
\text { seguem são as mais diversas, } \\
\text { sempre no contexto particular e } \\
\text { individual. Os usuários não sabem } \\
\text { quais são as regras teóricas, } \\
\text { também desconhecem dados dos } \\
\text { atributos da bacia hidrográfica. }\end{array}$ & $\begin{array}{l}\text { Não conhecem a bacia hidrográfica nos } \\
\text { aspectos biofísicos e sociais, de forma } \\
\text { ideal. Não conhecem as comunidades, seus } \\
\text { desejos e carências. Não conhecem os } \\
\text { atributos biofísicos do rio pois não tem } \\
\text { dados precisos e confiáveis para isso. }\end{array}$ \\
\hline $\begin{array}{l}\text { Princípio } 2 \text { - } \\
\text { Equivalência } \\
\text { Proporcional } \\
\text { entre Custos e } \\
\text { Benefícios }\end{array}$ & $\begin{array}{l}\text { Os usuários veem os investimentos } \\
\text { em conservação desnecessários e } \\
\text { onerosos. Não confiam nos órgãos } \\
\text { de gestão ambiental do governo. } \\
\text { Acham que os custos para cumprir } \\
\text { as regras impostas pelo governo } \\
\text { não são proporcionais à } \\
\text { contrapartida dada. Acham as } \\
\text { regras de preservação } \\
\text { implicitamente injus-tas, e não as } \\
\text { cumprem pois não há penalização } \\
\text { por isso. }\end{array}$ & $\begin{array}{l}\text { O CBHPIJ é formado por atores de governo, } \\
\text { dos usuários, e da sociedade civil } \\
\text { organizada. Os funcionários do governo } \\
\text { participam pois recebem diárias e tem } \\
\text { estrutura de veículos e outros à sua } \\
\text { disposição. Os usuários não se interessam } \\
\text { pelo assunto pois acham que o tempo e os } \\
\text { recursos são perdidos quando em plenária } \\
\text { coletiva. A sociedade civil organizada } \\
\text { também não tem recursos financeiros e } \\
\text { materiais para participar de modo mais } \\
\text { efetivo. }\end{array}$ \\
\hline $\begin{array}{ll}\text { Princípio } & 3 . \\
\text { Acordos de } \\
\text { Escolha } \\
\text { Coletiva. }\end{array}$ & $\begin{array}{l}\text { Os usuários não participam na } \\
\text { elaboração e preservação justa das } \\
\text { regras pois estão distantes da }\end{array}$ & $\begin{array}{l}\text { A organização coletiva CBHPIJ como dito no } \\
\text { princípio } 2 \text {, tem participação deficiente do } \\
\text { setor dos usuários. Os poucos usuários que } \\
\text { participam são de grandes empresas que }\end{array}$ \\
\hline
\end{tabular}




\begin{tabular}{|c|c|c|}
\hline & $\begin{array}{l}\text { realidade burocrática } \\
\text { sistema. }\end{array}$ & $\begin{array}{l}\text { utilizam a água e por isso defendem seus } \\
\text { interesses e não tem visão de classe. }\end{array}$ \\
\hline $\begin{array}{l}\text { Princípio } 4 . \\
\text { Monitoramento }\end{array}$ & $\begin{array}{l}\text { Os usuários se sentem livres de } \\
\text { fiscalização para usar os recursos } \\
\text { ambientais. Somente quando } \\
\text { surgem denúncias de vizinhos é } \\
\text { que o usuário se sente exposto à } \\
\text { fiscalização, mas isso só ocorre } \\
\text { quando há interrupção no fluxo da } \\
\text { água. No cotidiano não recebem } \\
\text { qualquer fiscal para a checagem do } \\
\text { cumprimento das regras. }\end{array}$ & $\begin{array}{l}\text { O CBHPIJ e os órgãos de monitoramento } \\
\text { não detêm de estrutura física e financeira } \\
\text { para exercer o monitoramento de uso dos } \\
\text { recursos hídricos de forma eficaz. Relatos } \\
\text { indicam apenas } 2 \text { fiscais para uma } \\
\text { abrangência próxima ao tamanho do país } \\
\text { Israel. Além disso, os agentes são vistos } \\
\text { como inimigos da população, já que os } \\
\text { usuários entendem que eles só buscam } \\
\text { punir, sem respeito a contrapartida que } \\
\text { deveria ser dada. }\end{array}$ \\
\hline $\begin{array}{l}\text { Princípio } \\
\text { Sanções } \\
\text { graduais }\end{array}$ & $\begin{array}{l}\text { As sanções apesar de } \\
\text { reconhecidamente graduais, não } \\
\text { exercem influência sobre os } \\
\text { usuários pelo importante fato de } \\
\text { inexistir monitoramento, logo não } \\
\text { existe sanção. Desta forma, os } \\
\text { usuários preferem seguir suas } \\
\text { próprias regras já que são mais } \\
\text { vantajosas financeiramente. }\end{array}$ & $\begin{array}{l}\text { Pelos problemas citados no princípio } 4 \text {, a } \\
\text { estrutura de gestão ambiental tem } \\
\text { deficiência na aplicação de sanções pois } \\
\text { não cumpre o monitoramento dos desvios } \\
\text { de conduta. As normas são elaboradas, } \\
\text { porém não se exige seu fiel efeito prático. }\end{array}$ \\
\hline $\begin{array}{lr}\text { Princípio } & 6 . \\
\text { Mecanismos } & \text { de } \\
\text { Resolução } & \text { de } \\
\text { Conflitos } & \end{array}$ & $\begin{array}{l}\text { Quando há discordância entre } \\
\text { vizinhos, quase sempre se localiza } \\
\text { no momento da escassez de água } \\
\text { (não muito comum, ainda). o } \\
\text { insatisfeito realiza denúncias aos } \\
\text { órgãos de gestão, em casos muito } \\
\text { pontuais, e quando elas se } \\
\text { acumulam, penalidades são } \\
\text { aplicadas. Não há local com } \\
\text { facilidade e agilidade para se } \\
\text { resolver os conflitos. }\end{array}$ & $\begin{array}{l}\text { A estrutura de gestão ambiental não } \\
\text { dispõe de mecanismos simplificados de } \\
\text { resolução de conflitos. Quando existem, } \\
\text { são ações administrativas ou judiciais } \\
\text { morosas e burocráticas. Quando se resolve } \\
\text { a querela, o dano ambiental já ocorreu, e } \\
\text { os danos sobram irreparáveis. }\end{array}$ \\
\hline $\begin{array}{l}\text { Princípio } 7 . \\
\text { Mínimo } \\
\text { reconhecimento } \\
\text { dos direitos }\end{array}$ & $\begin{array}{l}\text { Os usuários não confiam que } \\
\text { podem ajudar a confeccionar suas } \\
\text { próprias regras num objetivo } \\
\text { coletivo. Desta forma, acreditam } \\
\text { que não têm o mínimo } \\
\text { reconhecimento de seus direitos. }\end{array}$ & $\begin{array}{l}\text { Os membros da gestão acreditam que suas } \\
\text { vozes não são ouvidas pelo governo. } \\
\text { Acreditam que toda regra só é } \\
\text { aperfeiçoada se o governo concordar, } \\
\text { mesmo que seja construída de forma } \\
\text { coletiva. Se o governo discordar dos tratos } \\
\text { coletivamente acordados, os atores }\end{array}$ \\
\hline
\end{tabular}




\begin{tabular}{|l|l|l|}
\hline & & $\begin{array}{l}\text { acreditam que suas vontades não serão } \\
\text { acreditadas. }\end{array}$ \\
\hline $\begin{array}{l}\text { Princípio } 8.0 \text { Oços } \\
\text { cooperados }\end{array}$ & $\begin{array}{l}\text { Os usuários não notam a existência } \\
\text { de uma rede de entidades que } \\
\text { possam promover a gestão } \\
\text { ambiental adequada. Para eles, são } \\
\text { todas iguais, e defendem seus } \\
\text { próprios interesses. }\end{array}$ & $\begin{array}{l}\text { Os atores reconhecem que existe uma } \\
\text { estrutura de entidades em rede, porém } \\
\text { acreditam que elas são efêmeras, } \\
\text { desconectadas e temporais. }\end{array}$ \\
\hline
\end{tabular}

Fonte: Coleta direta de dados.

Como demonstrado pela interpretação qualitativa dos resultados da pesquisa apresentados acima, todos os princípios se mostraram frágeis, seja sob a ótica dos usuários ou sob a ótica dos agentes da gestão do CBHPIJ. Os membros da gestão não conhecem os limites geofísicos da bacia que administram. Os usuários não entendem como justos os custos e benefícios da opção em seguir as regras coletivas, não se acham pertencentes a um sistema que respeite suas crenças nas escolhas coletivas, sem monitoramento e correção de conduta ineficiente, dentro de um escopo de organizações soltas e isoladas.

Desse modo, a partir da comparação com os princípios de análise observa-se um conflito, uma desunião entre as categorias. Por exemplo, citamos o princípio 2. Os usuários veem os investimentos em conservação desnecessários e onerosos. Não confiam nos órgãos de gestão ambiental do governo. Argumentam que os custos para cumprir as regras impostas pelo governo não são proporcionais à contrapartida dada. Registram que as regras de preservação são implicitamente injustas, e não as cumprem pois não há penalização por isso. O CBHPIJ por sua vez não tem todo o seu corpo coletivo atuante pois, de certa forma, os ausentes não veem vantagem em participar. O corpo que representa o governo participa, pois são funcionários públicos delegados a esse fim, recebem diárias e tem estrutura de veículos e outros à sua disposição. Já os usuários, salvo algumas exceções, não veem vantagem em se interessar pelo assunto, pois entendem que o tempo e os recursos são perdidos em plenárias coletivas burocráticas e morosas. A terceira parte, não menos importante, os representantes da sociedade civil organizada, também não tem recursos financeiros e materiais para participar de modo mais efetivo, e de certa forma, não participa, pois terão "prejuízos" no aporte de tempo 
Dossiê | Governança dos comuns e conflitos na gestão da bacia do Rio Itanhém no extremo sul da Bahia (SOUZA,

Fernando Rios; MARTINS, Herbert Toledo)

e de finanças. Assim, todas as demais incongruências entre o coletivo e o individual estão representadas pelo Quadro 2, acima analisado.

Nesta perspectiva, a análise mostrou pela estrutura acima exposta que o Comitê é frágil e incapaz de coagir a ação egoísta individual, significando que o recurso comum está vulnerável à degradação. Este resultado é decorrente de uma má interação entre a governança e os usuários, afetando negativamente as formas de apropriação, a composição das regras, o monitoramento e a resolução de conflitos. Dessa relação, seguimos para os resultados e discussões do que isso representa para o equilíbrio socioambiental, e para a "saúde" do sistema de governança coletivo representado pelo CBHPIJ.

\section{Considerações finais}

Por que o CBHPIJ - Comitê de Bacias dos Rios Peruípe, Itanhém e Jucuruçu não concretiza as ações propostas após sete anos de funcionamento? Os resultados demonstram dois mundos paralelos e distantes. Um composto pela realidade prática dos usuários dos recursos comuns, onde envolve o cultivo, a criação de animais, as relações diretas com a terra e a extração da água; outro formado pelos plenários e reuniões burocráticas representadas pelo CBHPIJ, onde se discutem regras e teorias no campo abstrato. Os dados revelaram que, tanto os membros da gestão do CBHPIJ, quanto os usuários e demais membros da sociedade civil organizada, precisam se entender como complementares e pertencentes a um sistema de gestão policêntrico e de múltiplas camadas. Que este sistema precisa ser dinâmico, adaptativo e efetivo a curto, médio e longo prazo.

O CBHPIJ tem o desafio de melhorar sua comunicação e o processo de tomada de decisões, haja vista que para preservar é preciso inicialmente conhecer os limites biofísicos e sociais pertencentes ao sistema. As informações devem ser compartilhadas, discutidas coletivamente, levando-se em consideração que se trata de uma bacia hidrográfica grande, de múltiplas exigências, com muitas comunidades tradicionais, ricas e pobres. Devem ainda ser encurtadas as distâncias por meio das tecnologias, através de canais educativos de fácil acesso, que atinja os locais mais remotos, de modo 
Dossiê | Governança dos comuns e conflitos na gestão da bacia do Rio Itanhém no extremo sul da Bahia (SOUZA, Fernando Rios; MARTINS, Herbert Toledo)

que todos conheçam seus direitos e deveres, também as particularidades da região em que está inserido.

O CBHPIJ tem o desafio de ajudar a adequar melhor as regras que regem o uso do rio, pois as práticas não se mostraram suficientes a atender às necessidades e condições locais. Não está implantado a todos um senso de justiça, de modo que a execução das regras seja mais natural e motivada. Para piorar, os usuários acreditam que o estado não oferece a devida contrapartida em forma de melhoria de vida, além de ser um organismo caro, burocrático e desorganizado. Os usuários não confiam que o governo está interessado em equilibrar os pilares da sustentabilidade, mas, sim, apenas as contrapartidas inerentes a mais arrecadação.

Outro ponto a ser melhorado, caso o CBHPIJ queira se tornar fortalecido no cumprimento de seu dever da sustentabilidade, é o incentivo à reeducação coletiva dos indivíduos. O corpo precisa de indivíduos ativos, que participem das reuniões deliberativas, que faça presença e entenda que pode também participar de suas próprias regras. Regras estas que o CBHPIJ precisa ajudar a melhorar. O sistema precisa melhorar o processo de monitoramento e fiscalização no uso de seus recursos ambientais e do cumprimento das regras de preservação e recomposição natural. 0 monitoramento do uso da água não ocorre de modo claro e eficaz pelos competentes e, por isso, é preciso investir recursos financeiros e humanos permitindo que faça não só os agentes de governo, mas criando um sentimento de pertencimento ambiental, de modo que o cidadão possa sentir-se dono do bem coletivo, e se motive a ajudar, a preservar quando participa do monitoramento das regras e condutas dentro de sua comunidade. Como não há mecanismos simplificados para isso, e não há também o sentimento ideal de pertencimento, o indivíduo acaba não exercendo sua cidadania ajudando a denunciar os desvios e, também, a solucionar as dificuldades de forma rápida e desburocratizada, de modo que as soluções sejam mais preditivas possível.

Quanto ao processo de sanção pelo descumprimento das regras postas, crucial para o enfretamento das ações egoístas, o corpo de gestão mostrou um sistema teoricamente bem aperfeiçoado, mas pelas deficiências anteriores, os mecanismos locais e regionais de coerção não se apresentaram de modo a promover e garantir o cumprimento adequado das regras emanadas da gestão, o que enfraquece a cada dia o Comitê. Apesar de existir um sistema de colaboração multinível, com órgãos da 
Dossiê | Governança dos comuns e conflitos na gestão da bacia do Rio Itanhém no extremo sul da Bahia (SOUZA, Fernando Rios; MARTINS, Herbert Toledo)

sociedade e do governo, as regras se apresentam destoantes das necessidades sociais, com os usuários trabalhando de forma a cada um buscar seus exclusivos interesses. Não se organizam em rede, de forma conjunta e, por isso, não aumentam seu poder de resiliência, de troca de informações, seu processo de conhecimento e aprendizagem com os erros um do outro.

Finalmente, a análise mostrou que o CBHPIJ é uma das engrenagens que participa da permanência de uma crise socioambiental. Faz parte de um contexto retroalimentado de relações ruins entre as partes biofísicas, os usuários e a arena de ação. Um desmantelamento na estrutura de gestão ambiental que contribui com a permanência dos riscos à tragédia ambiental. O CBHPIJ precisa produzir resultados práticos suficientes para desconstruir a crise de confiança nos órgãos ambientais. Precisa fazer acontecer o modelo de gestão em que contribua para o desenvolvimento regional criando o sistema coletivo, já que ele representa a sociedade, simpático às questões que motivam ao indivíduo a ter satisfação em cooperar.

\section{Referências}

ACSERALD, Henri. As práticas espaciais e o campo dos conflitos ambientais. In: Conflitos Ambientais no Brasil/Organizador Henri Acserald - Rio de Janeiro: Relume Dumará: Fundação Heinrich Böll, 2004.

AZEVEDO, Aldemir; MARTINS, Herbert Toledo; DRUMMOND, José Augusto. A dinâmica institucional de uso comunitário dos produtos nativos do cerrado no município de Japonvar (Minas Gerais). Sociedade e Estado, v. 24, n.1, jan/abr. 2009.

BOURDIEU, Pierre. Os usos sociais da ciência: por uma sociologia clínica do campo científico. São Paulo: Editora Unesp, 2004.

HARDIN, Garrett. "The tragedy of the Commons". Science, v. 162, n. 3859, 1968,1243-1248.

MANCUR, Olson. The Logic of Collective Action: Public Goods and the Theory of Groups. Cambridge, MA: Harvard University Press,1965.

MEINZEN-DICK, Ruth. "Beyond panaceas in water institutions". Proceedings of the National Academy of Sciences of the United State of America, Vol. 104, No. 39 (Sep. 25, 2007), 15200-15205

OSTROM, Elinor. El Gobierno de los Bienes Comunes: la evolución de las Instituciones de Accion Colectiva. México: Fondo de Cultura Económica, 1990, p. 25-105.

OSTROM, Elinor. "Coping with tragedies of the commons". Annual Review of Political Science, v. 2, n. 1, 1999, 493-535. 
OSTROM, Elinor. "A General Framework for Analyzing Sustainability of SocialEcological Systems". Science, v. 325, n. 5939, 2009, 419-22.

PEREIRA, Elaine Aparecida Teixeira. O conceito de campo de Pierre Bourdieu: possibilidade de análise para pesquisas em história da educação brasileira. Revista Linhas. Florianópolis, v. 16, n. 32, p. 337 - 356, set./dez. 2015.

SANTOS, Márcio Soares; MARTINS, Herbert Toledo. Uma história ambiental da formação socioeconômica do extremo sul da Bahia (1948-1972). Maceió: VIII Congresso Internacional Interdisciplinar em Sociais e Humanidades (Coninter), Outubro/Novembro, 2019. 